\title{
Testosterone, prolactin, and oncogenic regulation of the prostate gland. A new concept: Testosterone-independent malignancy is the development of prolactin-dependent malignancy!
}

\author{
Leslie C. Costello, Renty B. Franklin \\ Department of Oncology and Diagnostic Sciences, University of Maryland School of Dentistry; and the University of \\ Maryland Greenebaum Cancer Center, Baltimore, MD, USA
}

\begin{abstract}
Hormone-independent malignancy is a major issue of morbidity and deaths that confronts prostate cancer. Despite decades of research, the oncogenic and hormonal implications in the development and progression of prostate malignancy remain mostly speculative. This is largely due to the absence and/or lack of consideration by contemporary clinicians and biomedical investigators regarding the established implications of the co-regulation of testosterone and prolactin in the development, maintenance, metabolism and functions of the prostate gland. Especially relevant is the major metabolic function of production of high levels of citrate by the peripheral zone acinar epithelial cells. Citrate production, along with growth and proliferation by these cells, is regulated by co-existing testosterone and prolactin signaling pathways; and by the oncogenic down-regulation of ZIP1 transporter/zinc/citrate in the development of malignancy. These relationships had not been considered in the issues of hormone-
\end{abstract}

Correspondence: Leslie C. Costello, Department of Oncology and Diagnostic Sciences, University of Maryland School of Dentistry, 650 West Baltimore Street, Baltimore, MD 21201, USA.

Tel.: +1.410.706.7618. E-mail: 1costello@umaryland.edu

Key words: Prostate cancer; hormone-dependent malignancy; prolactin and testosterone; citrate-producing acinar cells.

Acknowledgements: we appreciate the personal communication with Dr. John Kurhanewicz (UCSF) for his valuable expertise and important input regarding the study and interpretation of the MRSI report of Mueller-Lisse et al.38

Funding: the studies of LCC and RBF presented in this review were supported in part by NIH grants CA79903, DK076783 and DK42839 and AR064808.

Conflict of interest: the authors declare that there is no potential conflict of interest.

Received for publication: 3 February 2018

Accepted for publication: 13 June 2018.

This work is licensed under a Creative Commons Attribution NonCommercial 4.0 License (CC BY-NC 4.0).

CC Copyright L.C. Costello and R.B. Franklin., 2018

Licensee PAGEPress, Italy

Oncology Reviews 2018; 12:356

doi:10.4081/oncol.2018.356 dependent malignancy.

This review provides the relevant background that has established the dual role of testosterone and prolactin regulation of the prostate gland; which is essential to address the implications in the oncogenic development and progression of hormone-dependent malignancy. The oncogenic factor along with testosterone-dependent and prolactin-dependent relationships leads to the plausible concept that androgen ablation for the treatment of testosteronedependent malignancy results in the development of prolactindependent malignancy; which is testosterone-independent malignancy. Consequently, both testosterone ablation and prolactin ablation are required to prevent and/or abort terminal hormonedependent prostate cancer.

\section{Introduction}

This review is prompted by current issues regarding the role of testosterone and prolactin in the regulation of the development, maintenance, metabolism and functions of the prostate gland; and the implications in prostate cancer $(\mathrm{PCa})$. This applies to the major metabolic function of the prostate peripheral zone (PZ) acini (where malignancy develops) to produce high levels of zinc for secretion into prostatic fluid. ZIP1 zinc transporter uptake of zinc is required to produce the high levels of citrate. However, in virtually all cases of PCa, ZIP1/zinc/citrate is down-regulated; which is required to prevent the cytotoxic effects of high zinc levels in the malignant cells (for reviews). ${ }^{1-4}$ These are oncogenic and hormone dependent relationships, which impact the development of hormone-dependent malignancy and the basis for the treatment and prevention of PCa. Unfortunately, these relationships have been largely ignored by contemporary clinicians and biomedical investigators.

This review describes the important role of testosterone and prolactin in normal prostate and in $\mathrm{PCa}$; and presents the new concept of testosterone-dependent malignancy and prolactin-dependent (testosterone-independent) malignancy.

\section{A brief review of the role of zinc and citrate in normal prostate and prostate cancer}

Before describing the citrate relationships and hormonal regulation in normal prostate and prostate cancer, an understanding of the anatomic and functional organization of the human prostate is necessary (for extended reviews). ${ }^{1-4}$ 


\section{The organization of the human prostate gland}

The anatomic complexity of the human prostate gland has posed a challenge of more than 200 years of studies aimed at identifying its anatomic components and organization. ${ }^{5}$ Unresolved issues still remain regarding the identification and classification of the regional components of the human prostate gland. For this presentation, we employ a widely accepted description that includes the peripheral zone, the central zone, and the transition zone.

Most reported prostate studies have not considered the relevant relationships of the anatomic components of the human prostate gland. The human prostate gland has largely been considered or thought to be a uniform and homogeneous embryological, anatomical, and functional organ. This has resulted in questionable conclusions and translational misinterpretations of the physiological and pathophysiological relationships in humans.

The PZ comprises $\sim 70 \%$, and is the region where $\sim 90 \%$ of malignancies develop; the central zone comprises $\sim 25 \%$, and is the region of $\mathrm{BPH}$; the transition zone region comprises $\sim 5 \%$, and is the region where $\sim 10 \%$ of malignancies (somewhat indolent) develop and where BPH is initiated. These components are organized into a complex compact structure of the prostate gland, which make it difficult to separate and isolate specific tissue regions and cells for the identification and investigation of specific activities of the prostate gland.

Consequently, animal studies, which have separate regional lobes, have provided much of the information that has been applied to human prostate relationships. This is represented by the lateral, dorsal, and ventral lobes in mice and rats; which have been the most extensively employed animal models for translational representation of the human prostate gland. Most importantly, in regard to hormonal regulation of prostate development, growth, metabolism and function, the lateral lobe is the appropriate homologous and analogous representation of the human PZ. ${ }^{5}$ Both the ventral lobe (which has been most employed) and the dorsal lobe give different responses to hormone regulation; and these relationships especially apply to the issue citrate production. Therefore, many such studies have misrepresented those relationships as applied to the human prostate, due to the lack of consideration of the homology and analogy. The following presentation includes the appropriate human prostate representations of the animal studies.

\section{The status of zinc and citrate in normal prostate and prostate cancer}

The major role of prostate gland citrate production is the function of the highly specialized citrate-producing acini epithelial cells of the PZ. The capability of the epithelial cells to produce high levels of citrate is dependent on their capability to accumulate high levels of zinc. The zinc inhibits citrate oxidation; so the citrate is accumulated. Thus, these normal PZ epithelial cells are specialized zinc-accumulating, citrate-producing cells.

The zinc concentration is markedly decreased in malignancy in virtually all cases of $\mathrm{PCa}$, compared to normal and benign prostate. Many reported studies since first identified in $1954^{6}$ consistently demonstrated $\sim 70-90 \%$ decrease in zinc in PCa tissue; and no corroborated reports exist that have identified malignancy in $\mathrm{PCa}$ cases with the higher zinc level of the normal epithelial cells. This relationship also applies to the citrate levels. Therefore, PCa malignancy always exhibits the combination of decreased zinc and loss of citrate. ${ }^{3,6,7}$ Figure 1 shows the results of $x$-ray imagining of zinc in prostate biopsy samples, ${ }^{8}$ and the endorectal magnetic resonance imaging of citrate in the PZ. ${ }^{9}$ The citrate and zinc results are identical. In the combined 154 cancer cases represented in these independent studies, no case exhibited a zinc or citrate level comparable to the corresponding normal tissue; and for both zinc and citrate, a mean decrease of $\sim 90 \%$ exists in $\mathrm{PCa}$.

\section{The important role of ZIP1 transporter}

The concentration and distribution of zinc in all cells is regulated and maintained at conditions that are optimal for their normal growth, proliferation, metabolism, and functional activities. The ZIP-family (Slc39A) consists of plasma membrane transporters that facilitate the cellular uptake of zinc from interstitial fluid derived from plasma; which is the major source of cellular zinc (reviewed in ${ }^{10,11}$ ).

ZIP1 is the major functional transporter that is associated with the uptake and accumulation of the high zinc levels in the normal PZ acinar epithelial cells (Figure 2). In PCa, the malignant cells exhibit a marked downregulation of ZIP1 gene expression and decreased abundance of plasma membrane localized transporter. Zinc uptake and accumulation decreases concurrently with the downregulation of ZIP1.

Also important is that the decreased ZIP1/zinc/citrate occurs during premalignancy and in early malignancy, before the appearance of the histopatholgical identification of malignancy. It persists during progression in the prostate. Therefore, we now characterize $\mathrm{PCa}$ as a ZIP1-deficient malignancy in all cases of PCa.

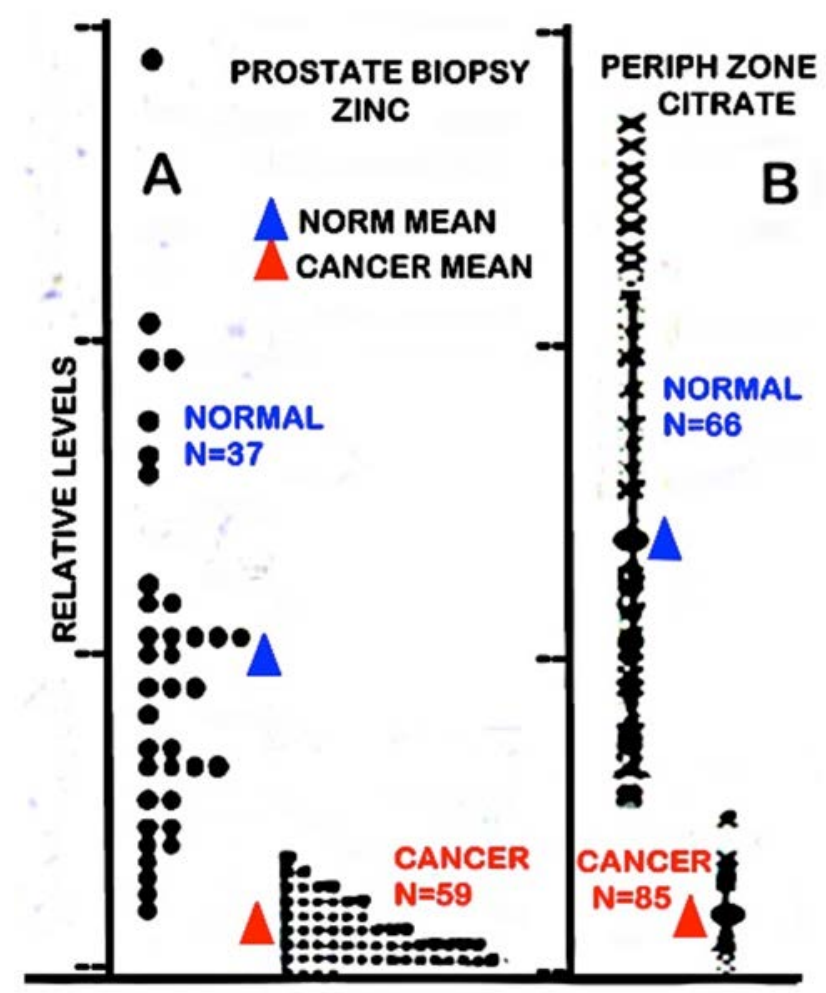

Figure 1. Zinc and citrate changes in prostate cancer subjects. A) Direct $x$-ray fluorescence of zinc in prostate biopsies (modified from $^{8}$ ). B.) In situ MRS imaging of citrate levels in the prostate gland (modified from $\left.{ }^{9}\right)$. 
Why is zinc always decreased in PCa malignancy?

The concentration of zinc that exists in the normal prostate epithelial cells is optimal for their activities. However, the concentration of zinc in the normal epithelial cells is cytotoxic in the malignant cells; and this applies to other malignant cells (for reviews). ${ }^{3,7,8,11}$ Therefore the evolution of the malignant cells involved adaptive mechanisms and conditions that reduce the concentration of zinc to a level that is not cytotoxic, and that maintains their growth, proliferation, and malignant activities. Thus, the genetic/metabolic transformation occurs in the early development of malignancy transformation; and is the reason that all cases of PCa must exhibit the decreased zinc in malignancy. $1,3,4$

The altered metabolic pathway of citrate production in the normal versus the malignant cells

The capability of high citrate production by the normal prostate epithelial cells, which we refer as net citrate production, requires unique metabolic alterations that deviate from the typical citrate metabolism that exists in mammalian cells (Figure 3). The most important and initial metabolic event is the ZIP1 uptake and accumulation of high zinc levels, which leads to the specific inhibition of $\mathrm{m}$-aconitase and prevents citrate oxidation via the Krebs cycle (i.e. a truncated Krebs cycle). This is accompanied by the upregulation of key enzymes and transporters (i.e. metabolic genes) that will provide continued citrate production.

Since ZIP1 is down regulated in the malignant cells, the zinc inhibition of m-aconitase is alleviated; and the specialized genetic/metabolic events for net citrate production are no longer required. Thus the normal Krebs cycle is restored, and the malignant cells exhibit the typical citrate oxidation.

\section{Testosterone and prolactin; the major endocrine regulation of normal prostate citrate production}

It has been well recognized from human and animal studies that testosterone is a major hormone for the regulation of the growth and maintenance of the prostate gland. Studies in animals and with human prostate cell lines have consistently demonstrated that prolactin is also a major regulator of the growth and development of the prostate gland.

However, that zinc and citrate levels are also regulated by testosterone and prolactin ${ }^{12,13}$ has been largely ignored by contemporary clinicians and biomedical investigators. Both hormones regulate the metabolic pathway and the expression of the metabolic genes shown in Figure 3. In animal and human cells, both hormone pathways co-exist in the same epithelial cell; not in separate cells. In addition, the promotor regions of the metabolic genes, as represented by mAAT, contain the androgen and prolactin response elements that manifest their stimulation of the gene expression. ${ }^{13}$ This dual regulation by a steroid hormone and a protein hormone emphasizes the importance of the metabolic functional role of prostate citrate production.

Testosterone regulation of the expression of the metabolic genes involved in net citrate production by the normal prostate epithelial cells

The testosterone regulation of the metabolic genes is generally in accord with the established pathway for testosterone trophic effects. Figure 4 presents the regulation of mAAT, which is representative of testosterone metabolic gene regulation.
Prolactin regulation of the expression of the metabolic genes involved in net citrate production by the normal prostate epithelial cells

Unlike testosterone, prolactin cytokine regulation (e.g. development, growth, proliferation) and its regulation of the metabolic genes occur by different signaling pathways. The cytokine regulation generally requires a JAK/STAT/MAPK cascading signaling

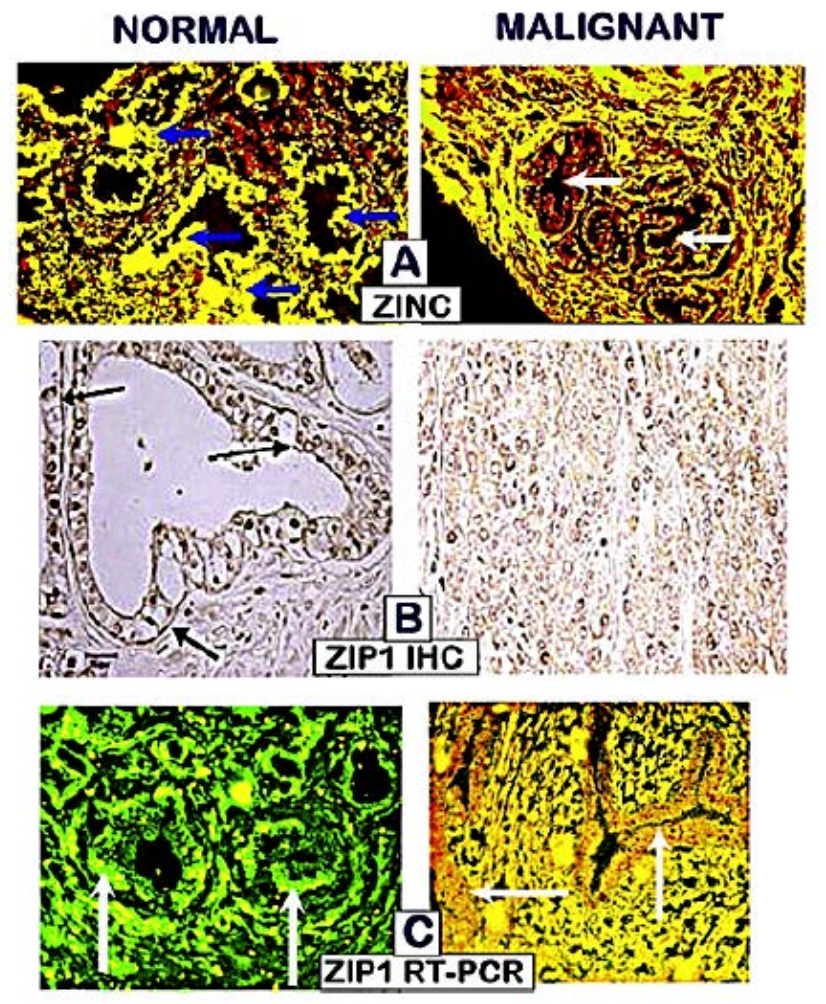

Figure 2. A) The loss of zinc. B) The loss of ZIP1 transporter; C) The silencing of ZIP1 expression; in early grade prostate cancer.

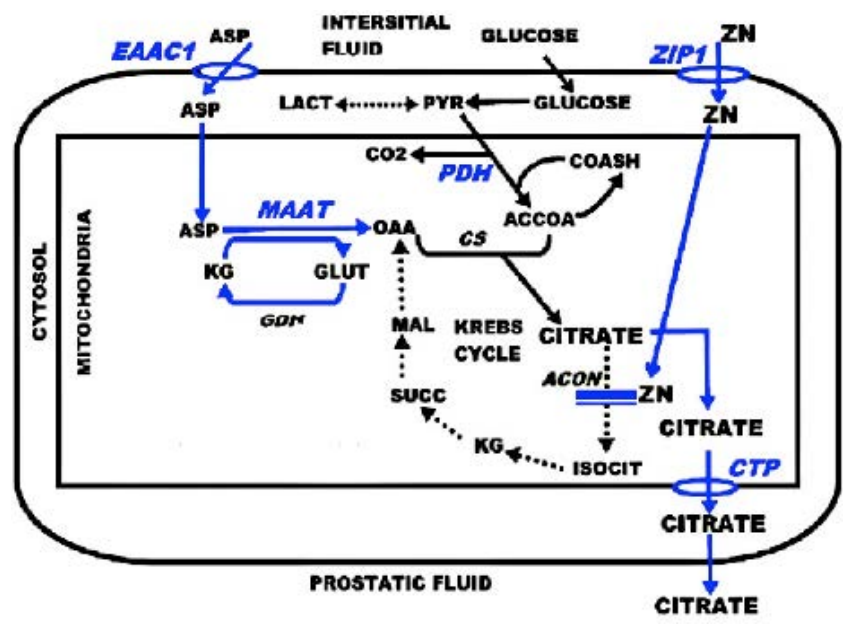

Figure 3. The metabolic transformation for citrate-producing acinar epithelial cells. Blue, key reactions; EAAC, Asp transporter; ZIP1, zinc transporter; MAAT, Asp aminotransferase; PDH, pyruvate dehydrogenase; ACON, aconitase; CTP, mito citrate transporter protein. 
pathway of immediate-early genes, intermediate genes, and lateacting (effector) genes (Figure 5). This is necessary to achieve the high abundance of the final products, and the integration of the related gene products that are necessary to manifest its cytokine effect. This is a complex process that occurs over a relatively extended period of time.

In contrast, the regulation of the metabolic genes requires the rapid production of the gene products (enzyme/transporter) to manifest its cellular metabolic reaction, and this is achieved by the direct prolactin PKC signaling pathway (Figure 6). In addition, these enzyme and transporter exist in low abundance (nanomolarmicromolar concentrations). To achieve these requirements, prolactin regulation of the metabolic genes employs a direct PKC pathway in which the immediate-early genes are the effector genes, whose products are the enzymes and transporters. The Michaelis-Menton kinetics of these metabolic enzymes and transporters dictate that increased abundance greater than their Vmax will not significantly increase their activity; so that increased gene expression of $\sim 2$-fold or less will have a significant increased metabolic activity. ${ }^{14}$

Unfortunately, the prolactin role and pathway of regulation of prostate citrate-production has been largely ignored by contemporary clinicians and biomedical investigators. This has resulted in erroneous and untenable views that prolactin regulation of all prostate functions occur via the complex cytokine pathway. This is apparent from conclusions in contemporary reports and reviews (such as ${ }^{15}$ ) that STAT5 is the only PRLR signaling pathway that is activated to detectable levels by PRL in the prostate.

Since this is a most important relationship for normal prostate and its implications in prostate malignancy, the following presents the compelling supporting evidence regarding the direct PKC pathway for prolactin regulation of the prostate metabolic genes. ${ }^{13}$ i) Exposure of prostate cells to prolactin and to TPA (phorbol-12myristate-13-acetate) increases PKC activation within five minutes, which is immediately followed by increased transcription of the metabolic gene. ii) This stimulatory effect is abolished by PKC inhibitors gossypol and staurosporine. iii) Prolactin specifically activates two (PKC $\alpha$ and $\mathrm{PKC} \varepsilon$ ) of the eight $\mathrm{PKC}$ isoforms that

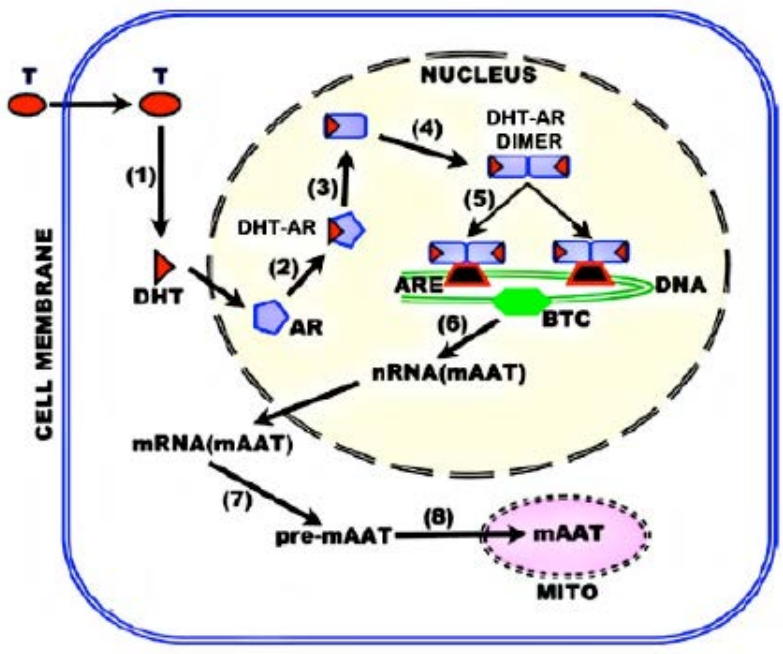

Figure 4. Testosterone regulation of metabolic genes in citrateproducing prostate cells. BTC, basal transcription complex. were identified in prostate epithelial cells. iv) $\mathrm{PKC} \varepsilon$ antisense abolishes prolactin stimulation of the metabolic gene. v) TPAresponse elements exist in the regulatory region of the metabolic genes. vi) The inhibition of PKC $\varepsilon$ expression decreases the activation and nuclear protein binding to the metabolic gene TRE in response to prolactin. vii) The down regulation of PKC does not inhibit the prolactin effect on proliferation; but inhibits the effect on the metabolic genes. viii) AG490 inhibition of the JAK/STAT3

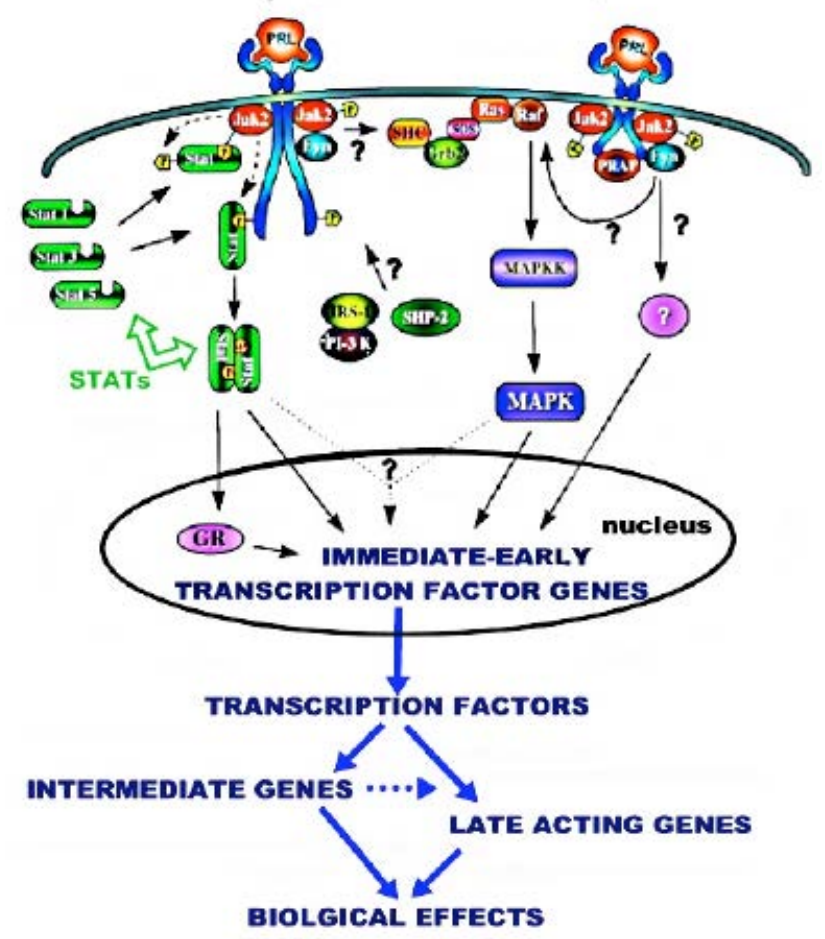

Figure 5. Representative Jak/Stat/MAPK cytokine pathway for prolactin regulation of prostate cells.

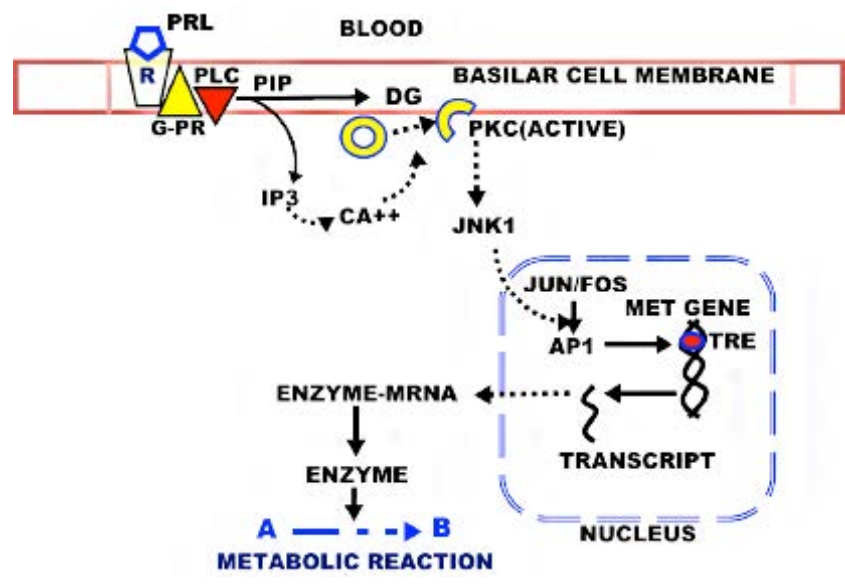

Figure 6. The PKC pathway for prolactin regulation of the metabolic genes for citrate-producing prostate cells. $R$, PRL receptor; G-PR, G-protein coupled receptor; PLC, phospholipase C; PIP, phosphatidylinositol phosphate; PIP3, Inositol triphosphate; DAG, diacylglycerol; PKC, phosphokinase C; JNK1, c-Jun Nterminal kinase; AP1, Activator Protein 1 Transcription factor; TRE, TPA response element. 
pathway has no effect on the prolactin regulation of citrate production. ix) prolactin treatment rapidly increases the level of phosphorylated c-jun. Collectively, these relationships establish the PKC mediated pathway for prolactin regulation of metabolic genes involved prostate citrate production.

\section{The genetic/metabolic concept of the oncogenic development of prostate malignancy}

The issue of the hormonal dependency of PCa malignancy requires an understanding of the oncogenic events in the development of malignancy. We have established that the ZIP1/zinc/citrate relationship, which exists in the normal acini epithelial cells, is down-regulated in the development of malignancy. ${ }^{16}$ This is essential to prevent the cytotoxic effects of the higher zinc levels that exist in the normal cells. We incorporate this relationship in our concept of the oncogenic development of malignancy as represented in Figure 7. The initiating event is the oncogenic transformation of the normal cell to a neoplastic cell that has malignant potential. The neoplastic cell then undergoes genetic/metabolic transformations to a premalignant cell; which leads to its development as a malignant cell that manifests the malignant activities. This relationship shows that the downregulation of the ZIP1/zinc/citrate transformation is evident in premalignancy and its development of the malignant cells, as our studies have demonstrated occurs in all cases of $\mathrm{PCa}$.

Then the issue becomes the upstream factor(s) that lead to the downregulation of ZIP1. We have established that the hZIP1gene contains RREB1 (ras-responsive binding protein 1) binding sites; and that RREB1 binding results in decreased ZIP1 transcription. ${ }^{17,18}$ Our studies with IHC staining of human prostate tissue sections have shown that the loss of ZIP1 transporter in the malignant epithelial cells is accompanied by the up-regulation of RREB1 in all eight PCa cases in this study. ${ }^{18}$

Although the upstream factor(s) and signaling pathway are not well established (and no other studies of prostate cancer exist) for the regulation of RREB1, it is thought to involve the RAS $\rightarrow \rightarrow$ ERK pathway. Nevertheless, it is evident that RREB1 regulation is coupled to the oncogenic initiation of malignancy as represented in Figure 7B. It is also possible that ZIP1 expression might involve other oncogenic factors. In any event, it is apparent that the oncogenic down-regulation of ZIP1 is independent of testosterone and prolactin; and that the oncogenic down-regulation over-rides the testosterone and prolactin effect in promoting the expression of ZIP1 for zinc accumulation and citrate production.

\section{Hormonal regulation of citrate production of nor- mal human prostate and prostate cancer}

The status and regulation of citrate in the normal prostate PZ epithelial cells and in malignant cells need to be established for this presentation. This is achieved from the direct studies with human prostate, studies with animals, studies with human and animal cells.

\section{Testosterone regulation}

The studies in animal models and with animal and human prostate cells have consistently demonstrated that testosterone regulates the metabolic pathway for citrate production. Dr. Huggins received the Noble Prize in 1966 for his studies that demonstrated testosterone promotion of $\mathrm{PCa}$; and the regression of malignancy following testosterone ablation. Marberger et al. in $1962^{19}$ determined that primary site malignancy and metastatic malignancy exhibit decreased citrate; and Cooper and Farid in $1963^{20}$ also identified the decreased citrate in PCa. That testosterone regulates citrate production in animals has been established by several early studies. ${ }^{21-23}$ Our studies, beginning $\sim 1975$ (described above), established the identification of the citrate producing metabolic pathway and its regulation by testosterone.

This led to the development of endorectal magnetic resonance spectroscopy imaging (MRSI) of the prostate gland, which directly identifies and confirms the production of high levels of citrate in the normal PZ; and the loss of detectable citrate in malignancy (Figure 8) (for reviews ${ }^{24,25}$ ). High citrate exists only in normal acini epithelial cells, and all other cells in the PZ contain the low concentrations of citrate typically found in normal mammalian cells. This is shown in the voxels of the normal peripheral tissue, and the voxels of malignant tissue that contain very low citrate levels. The latter results from the oncogenic down-regulation of ZIP1/zinc/citrate in the development of malignancy.

\section{Prolactin regulation}

Unlike testosterone, direct studies of prolactin regulation of human prostate citrate production are lacking; mainly due to its
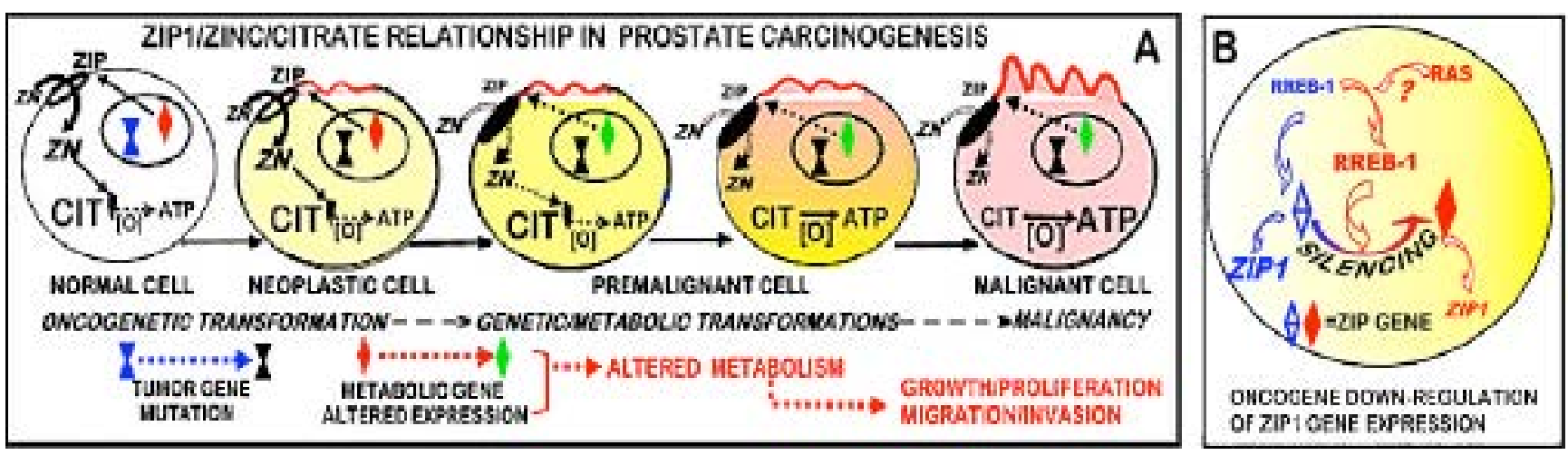

Figure 7. The down-regulation of ZIP1/zinc/citrate in the oncogenic transformation that is required for the development and progression of prostate malignancy. 
anterior pituitary origin; its peptide nature, and its limitations as a medication for prostatic conditions. Consequently, studies with animal models and with animal and human prostate cells must be employed as representation of the likely conditions relating to the role of prolactin in humans. This requires the appropriate models and results that will provide compelling evidence for prolactin regulation of human prostate citrate production. The following provides such evidence:

i) Human prostate: Nevalainen et al. ${ }^{26}$ had demonstrated prolactin and prolactin receptor expression in human prostate.

ii) Animal studies: Grayhack et al. ${ }^{27}$ was the first to show that prolactin and testosterone increased citrate levels in the lateral prostate. Our studies ${ }^{13}$ and the report of Rui and Purvis ${ }^{28}$ have confirmed the stimulation of citrate production by prolactin and testosterone in rat lateral prostate; and that these are independent effects of each hormone. That the rat lateral prostate exhibits homology and analogy with the human PZ, strengthens the relationship.

In studies with bonnet monkeys, Arunakaran et al. ${ }^{23}$ established that prolactin and testosterone stimulates prostate citrate production and the metabolic genes; and that the prolactin was found to have a direct as well as a synergistic effect with androgen.

Thus all animal studies of prostate citrate production have consistently demonstrated a co-existence of regulation by prolactin and by testosterone in the prostate cells.

iii) Studies with cells: In vitro studies with isolated rat prostate cells and human prostate cell lines have demonstrated both the coexistence of prolactin and testosterone regulation of prostate citrate production; and both hormones exhibit identical effects on the regulation of the metabolic genes, and on the accumulation of zinc.

Especially notable is the hormonal regulation in $\mathrm{LNCaP}$ and PC-3 cell lines. LNCaP cells express androgen receptor, whereas PC-3 cells do not. Our studies ${ }^{13,29,30}$ of the regulation of aspartate transporter (EAAC1) showed that aspartate transport was significantly increased by both testosterone and prolactin in LNCaP cells. In contrast, aspartate zinc accumulation in PC-3 cells was significantly increased by prolactin, but testosterone had no significant effect. When the PC-3 cells were transfected with androgen receptor, testosterone significantly increased zinc accumulation. These studies with human prostate cell lines demonstrate the independent effect of prolactin regulation; and the co-regulation by prolactin and testosterone on the prostate cells.

Collectively, these studies present compelling evidence for the important role of prolactin, along with testosterone on human prostate citrate-production. To consider otherwise requires the conclusion that the testosterone regulation in humans is consistent with the animal and cell studies; but in regard to co-existing prolactin regulation, it is uniquely different from the same animal and cell studies. Such an expectation and conclusion are highly implausible.

\section{The role of testosterone and prolactin in hormone- dependent malignancy}

The factors involved in the major issue of the development of hormone-independent malignancy have been a focus of research for decades. Studies to determine the factors and mechanisms have been concentrated predominantly on androgen regulation; especially the status of androgen receptor during androgen-independent malignancy following androgen ablation. As proposed by Quigley et $a .^{31}$ the androgen receptor gene exhibits more mutations than that of any other transcription factor; due to the fact that the AR is encoded by a single copy X-chromosomal gene (it is the only Xchromosomal steroid receptor gene). There is near consensus that

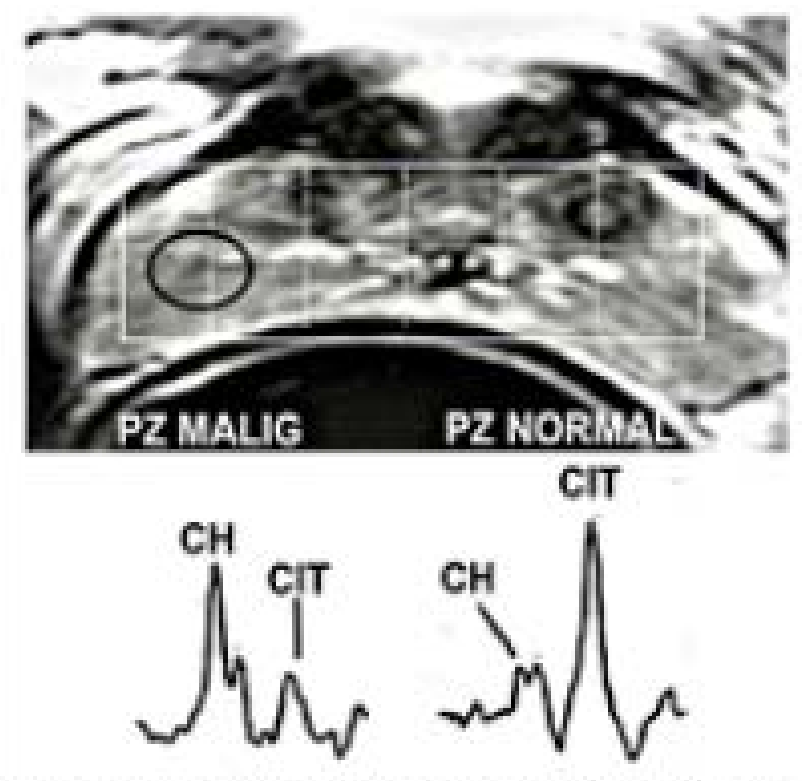

\section{MRS IMAGING OF PERIPHERAL ZONE}

Figure 8. In situ MRSI showing high citrate in normal PZ and decreased citrate in the malignant site of the PZ. Ch, choline.

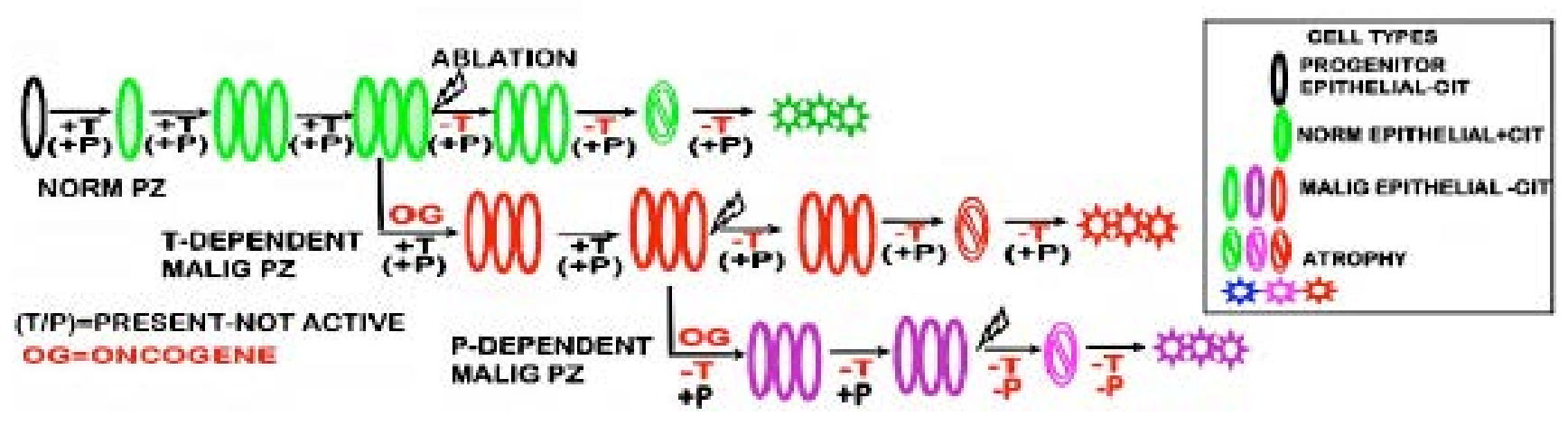

Figure 9. Concept of the development of testosterone-dependent malignancy; and development of prolactin-dependent (testosteroneindependent) malignancy following testosterone ablation. 
androgen receptor mutations are largely implicated in the decreased testosterone that develops during hormone-independent malignancy. ${ }^{32-34}$

The reason for this is the prevailing view that the hormonal regulation of development, maintenance, and function of the normal human prostate gland, and malignant prostate, is the exclusive dependency on testosterone. Therefore, the development of therapies (such as LHRH agonist and antiandrogen) have been targeted on the elimination of testosterone and its effects; thereby resulting in atrophy of the normal and malignant tissue. Yet, no efficacious therapy exists that prevents the development of androgen-independent malignancy.

Thus, the question is: Why?. A plausible consideration is that another hormone is associated with the regulation of the prostate gland, and is implicated in the development of malignancy. The compelling evidence of co-existing testosterone and prolactin regulated pathways of citrate production in the PZ epithelial cells should be considered in relation to hormone-dependent malignancy. Unfortunately, this important established relationship has been largely ignored.

\section{New concept: PCa includes testosterone-dependent malignancy and prolactin-dependent (i.e. testosterone- independent) malignancy}

Based on the relationships that we have thus far presented, and that which follows, we propose that testosterone and prolactin are involved in the development and progression of malignancy.

The importance of the ZIP1/zinc/citrate relationship must be emphasized. This pathway exists in the normal PZ acini to provide the production and secretion of high citrate levels in the prostatic fluid, and is regulated by testosterone and prolactin. However for malignancy to develop, the zinc levels have to be decreased to prevent its cytotoxic effects in malignant cells. This requires the oncogenic down-regulation of ZIP1/zinc. This also results in decreased citrate since the decreased zinc alleviates the inhibition of $\mathrm{m}$ aconitase; so that citrate oxidation via the Krebs cycle is active. Therefore, the citrate level is a perfect metabolic marker for the events of malignancy.

Normal or near-normal levels of testosterone and prolactin exist in individuals prior to the development of PCa. Notably, during aging, testosterone levels decrease and prolactin levels increase. ${ }^{35}$ The integrity of the prostate tissue and its functional/metabolic activities (such as citrate production) is maintained by testosterone; which indicates that the presence of testosterone suppresses the regulation by prolactin. In the absence of testosterone, its suppression of prolactin regulation is alleviated and prolactin-dependent regulation of the prostate occurs. This is a reason why the citrate-producing cells exhibit co-existing testosterone and prolactin pathways. Reported studies ( such as $^{36,37}$ ) have shown cross-talk between the two pathways (possibly mediated by the status of androgen and/or prolactin receptor). No evidence exists for separate prostate cells that contain only testosterone pathway, and prostate cells that contain only prolactin pathway, for the regulation of citrate production.

These relationships provide the basis for our new concept of hormone-dependent malignancy in $\mathrm{PCa}$, which is represented in Figure 9. When PCa develops, oncogenic down-regulation of ZIP1/zinc/citrate occurs; and leads to malignancy as shown in Figure 7. This is testosterone-dependent malignancy because testosterone maintains and promotes proliferation of the normal and malignant acini epithelial cells. Testosterone ablation results in the down-regulation of ZIP1/zinc/citrate in the PZ normal epithelial cells followed by atrophy of the cells. The malignant cells, which had already undergone oncogene down-regulation of
ZIP1/zinc/citrate, also atrophy in the absence of testosterone. At the end of the androgen ablation effects, testosterone-dependent acinar epithelial cells and the malignant cells no longer exists; and this has occurred in the presence of prolactin.

Then the progression of malignancy proceeds in the absence of testosterone; which removes its suppression of prolactin regulation. The malignant cells that exist soon after the initiation of testosterone are then maintained and proliferate as prolactindependent (testosterone-independent) malignancy. Prolactin ablation then results in the atrophy of these cells.

This concept is supported by the MRSI study of Mueller-Lisse et al. ${ }^{38}$ of the time-dependent changes in citrate and atrophy of normal and malignant PZ in androgen ablation-treated patients with nonmetastatic, localized PCa. They observed that the loss of citrate occurs prior to the subsequent atrophy of the normal and malignant cells following androgen ablation. This is due to the absence of testosterone regulation of citrate production and tissue maintenance of the PZ. (Note: In a personal communication, Dr. Kurhanewicz, co-author with Mueller-Lisse et al., agreed that this is a reasonable interpretation of their study; see Acknowledgements).

It is also notable that at the end of the 34-week post-androgen ablation period, when testosterone dependent atrophy of the PZ tissue of this study had occurred, there remained citrate tissue in the normal and malignant regions of the PZ. This likely represents the development of androgen-independent citrate-producing acini, in which the oncogenic transformation has been initiated during the extended period of the absence of testosterone. We propose that this represents prolactin-dependency, which over time promotes and maintains proliferation of the androgen-independent malignancy. Therefore, prolactin ablation is required to abort the progression of malignancy.

The relationships that we have described and represented in Figure 9, propose that the presence of testosterone regulation suppresses the regulation by prolactin. An alternative possibility is that both testosterone and prolactin regulation are co-actively operational; and the optimal regulation is achieved when both hormones are available. Then, in the absence of testosterone following androgen ablation, prolactin-dependency prevails. Over an extended period of post-androgen ablation, prolactin maintenance and proliferation of the PZ cells progresses. This would also be consistent with reports of synergy between testosterone and prolactin regulation of the prostate in animal studies (such as ${ }^{39-41}$ ).

Nevertheless, in either of the above possibilities, the evidence for prolactin-dependent malignancy following androgen-ablation is well-founded based on the collective reported animal and human prostate studies. This supports the concept that prolactin-ablation is necessary to prevent or terminate the androgen-independent malignancy.

\section{The impact on the treatment for advancing prostate malignancy}

Of course, the prevention and/or treatment of early malignancy is the optimal achievement. Once the primary site malignancy has progressed beyond effective localized treatment, or has advanced to metastasis, androgen ablation is targeted to abort the existing malignancy. However, this introduces the problem of the development and treatment of the androgen-independent malignancy that follows; for which no efficacious treatment currently exists.

We have proposed a zinc treatment approach based on restoring the accumulation of zinc and its cytotoxic effects in the ZIP1deficient malignant cells. This approach should be efficacious at any stage from premalignant/early malignancy through advancing primary site malignancy; and even metastatic malignancy; which 
reportedly exhibits the Zip1/zinc/citrate relationship. ${ }^{19,42}$ It should be effective against androgen-dependent and prolactin-dependent malignancy. Our studies ${ }^{43,44}$ with the zinc ionophore treatment for ZIP1-deficient PC-3 tumors in the xenograft mouse model have shown an $\sim 80 \%$ inhibition of tumor growth.

The expectation that prolactin-responsive malignancy occurs in human PCa leads to a prolactin ablation treatment approach. Our studies and others described above have demonstrated that bromocryptine treatment to inhibit prolactin production, attenuates prolactin stimulation of citrate production in animals and in cells. Similarly, hyperproloactinemia associated with prolactinomas in females is effectively treated with cabergoline (a bromocryptinelike dopamine agonist). ${ }^{45-47}$ A preliminary study ${ }^{48}$ suggests that cabergoline treatment might be effective for breast cancer. The possibility exists that cabergoline (or similar compound) could be combined with androgen ablation or subsequent to androgen ablation, which will result in atrophy of androgen-dependent and prolactin-dependent malignant cells.

\section{Conclusions}

Although the importance of testosterone in the development and maintenance of the prostate gland has been well recognized; its major metabolic/functional role of prostate citrate production has been ignored by most contemporary clinicians and biomedical investigators.

The importance of prolactin in the development and maintenance of the prostate gland has received little attention; and its well-established role in prostate citrate production has been completely ignored.

Thus, the contemporary understanding and views of the hormonal regulation of the prostate gland, and the implications in hormone-dependent malignancy are questionable and likely to be untenable. This new concept recognizes and incorporates the compelling evidence of co-existing testosterone and prolactin roles in the regulation of the prostate gland; along with our concept of the oncogenic development of prostate malignancy. This relationship should be incorporated for the prevention and treatment of hormone-dependent malignancy. Studies with appropriate animal models and clinical trials are now needed to establish the plausibility of this concept. The eradication of hormone-dependent untreatable terminal PCa is achievable.

\section{References}

1. Costello LC, Franklin RB. A comprehensive review of the role of zinc in normal prostate function and metabolism; and its implications in prostate cancer. Arch Biochem Biophysics 2016;611:100-12.

2. Costello LC, Franklin RB. The intermediary metabolism of the prostate: a key to understanding the pathogenesis and progression of prostate malignancy. Oncology 2000;59:269-82.

3. Costello LC, Franklin RB. The clinical relevance of the metabolism of prostate cancer; zinc and tumor suppression: connecting the dots. Mol Cancer 2006;5:17.

4. Costello LC, Franklin RB. Cytotoxic/tumor suppressor role of zinc for the treatment of cancer: an enigma and an opportunity. Expert Rev Anticancer Ther 2012;12:121-8.

5. Timms BG. Prostate development: a historical perspective. Differentiation 2008;76:565-77.

6. Mawson CA, Fischer MI. The occurrence of zinc in the human prostate gland. J Med Sci 1952;30:336-9.

7. Costello LC, Franklin RB. Zinc is decreased in prostate cancer: an established relationship of prostate cancer! J Biolog Inorganic Chem 2011;16:3-8.

8. Zaichick VY, Sviridova TV, Zaichick SV. Zinc in the human prostate gland: normal hyperplasia, cancerous. Int Urol Nephrol 1997;29:565-74.

9. Kurhanewicz J, Vigneron DB, Males RG, et al. The prostate: Imaging and spectroscopy. Radiol Clin North Am 2000;38:115-38.

10. Gaither LA, Eide DJ. Eukaryotic zinc transporters and their regulation. Bometals 2001;14:251-70.

11. Franklin RB, Milon B, Feng P, et al. Zinc and zinc transporters in normal prostate and the pathogenesis of prostate cancer. Front Biosci 2005;10:2230-9.

12. Costello LC, Franklin RB. Concepts of citrate production and secretion by prostate: 2 . Hormonal relationships in normal and neoplastic prostate. Prostate 1991;19:181-205.

13. Costello LC, Franklin RB. Testosterone and prolactin regulation of metabolic genes and citrate metabolism of prostate epithelial cells. Horm Metabol Res 2002;34:417-24.

14. Costello LC, Franklin RB. Integration of molecular genetics and proteomics with cell metabolism: how to proceed; how not to proceed! Gene 2011;486:88-93.

15. Goffin V. Prolactin receptor targeting in breast and prostate cancers: new insights into an old challenge. Pharmacol Ther 2017; 179:111-26.

16. Franklin RB, Levy BA, Zou J, et al. ZIP14 zinc transporter downregulation and zinc depletion in the development and progression of hepatocellular cancer. J Gastrointest Cancer 2012;43:249-57.

17. Milon BC, Agyapong A, Bautista R, et al. Ras responsive element binding protein-1 (RREB-1) down-regulates hZIP1 expression in prostate cancer cells. Prostate 2010;70:288-96.

18. Zou J, Milon BC, Desouki MM, et al. hZIP1 zinc transporter down-regulation in prostate cancer involves the overexpression of ras responsive element binding protein-1 (RREB-1). Prostate 2011;71:1518-24.

19. Marberger H, Marberger E, Mann T, et al. Citric acid in human prostatic secretion and metastasizing cancer of prostate gland. Br Med J 1962;1:835-6.

20. Cooper JE, Farid I. The role of citric acid in the physiology of the prostate: lactic/citrate ratios in benign and malignant prostatic homogenates as an index of prostatic malignancy. J Urol 1964;92:533-6.

21. Mann T, Lutwak-Mann C. Secretory function of male accessory organs of reproduction in mammals. Physiol Rev 1951;31:27-55.

22. Grayhack JT. Effect of testosterone, estradiol administration on citric acid and fructose content of the rat prostate. Endocrinol 1965;77:1068-74.

23. Arunakaran J, Aruldhas MM, Govindarajulu P. Effect of prolactin and androgens on the prostate of bonnet monkeys, macaca radiata: I. nucleic acids phosphatases and citric acid. Prostate 1987;10:265-73.

24. Costello L, Franklin RB, Kurhanewicz J. The metabolic characterization of prostate malignancy by magnetic resonance spectroscopy. In: Encyclopedia of Cancer, Academic Press; 2002, 3:167-77.

25. Kurhanewicz J, Vigneron DB. Advances in MR spectroscopy of the prostate. Magn Reson Imaging Clin N Am 2008;16:697710 .

26. Nevalainen MT, Valve EM, Mäkelä SI, et al. Prolactin effects, prolactin, and prolactin receptor expression in human prostate. 
Endocrinol 1991;129:612-22.

27. Grayhack JT, Lebowitz A. Effect of prolactin on citric acid of lateral lobe of prostate of SpragueDawley rats. Invest Urol 1967;5:7-9.

28. Rui H, Purvis K. Hormonal control of prostate function. Scand J Urol Nephrol Suppl 1988;107:32-8.

29. Franklin RB, Zou J, Gorski E, et al. Prolactin regulation of mitochondrial aspartate aminotransferase and protein kinase $\mathrm{C}$ in human prostate cancer cells. Mol Cell Endocrinol 1997; 127:19-25.

30. Gorski E, Zou J, Costello LC, Franklin RB. Protein kinase c mediates prolactin regulation of mitochondrial aspartate aminotransferase gene expression in prostate cells. Mol Urol 1999;3:17-23.

31. Quigley CA, De Bellis A, Marschke KB, et al. Androgen receptor defects: historical, clinical, and molecular perspectives. Endocr Rev 1995;16:271-321.

32. Ruijter E, van de Kaa C, Miller G, et al. Molecular genetics and epidemiology of prostate carcinoma. An extensive review of the mutations found in prostate cancers. Endocr Rev 1999;20:22-45.

33. Feldman BJ, Feldman D. The development of androgen-independent prostate cancer. Nat Rev Cancer 2001;1:34-45.

34. Dehm SM, Tindall DJ. Regulation of androgen receptor signaling in prostate cancer. Expert Rev Anticancer Ther 2005;5:6374.

35. Van Coppenolle F, Slomianny C, Carpentier F, et al. Effects of hyperprolactinemia on rat prostate growth: evidence of androgeno-dependence. Am J Physiol Endocrinol Metab 2001;280:E120-9.

36. Prins GS. Prolactin influence on cytosol and nuclear androgen receptors in the ventral, dorsal, and lateral lobes of the rat prostate. Endocrinol 1987;120:1457-64.

37. Nevalainen MT. Prolactin is a survival factor for androgen deprived rat dorsal and lateral prostate epithelium in organ culture. Endocrinol 1999;140:5412-21.

38. Mueller-Lisse UG, Swanson MG, Vigneron DB, et al. Magnetic resonance spectroscopy in patients with locally con- fined prostate cancer: association of prostatic citrate and metabolic atrophy with time on hormone deprivation therapy, PSA level, and biopsy Gleason score. Eur Radiol 2007;17:371-8.

39. Thomas JA, Keenan EJ. Prolactin influences upon androgen action in male accessory sex organs. Adv Sex Horm Res 1976;2:425-70.

40. Arunakaran J, Balasubramanian K, Srinivasan N, et al. Effects of prolactin and androgens on enzymes of carbohydrate metabolism in prostate of castrated bonnet monkeys Macaca radiata (Geoffroy). Indian J Exp Biol 1992;30:8-11.

41. Reiter E, Lardinois S, Klug M, et al. Androgen-independent effects of prolactin on the different lobes of the immature rat prostate. Mol Cell Endocrinol 1995;112:113-22.

42. Costello LC, Franklin RB, Zou J, et al. Human prostate cancer ZIP1/zinc/citrate genetic/metabolic relationship in the TRAMP prostate cancer animal model. Cancer Biol Ther 2011;12:107884.

43. Costello LC, Franklin RB, Zou J, et al. Evidence that human prostate cancer is a ZIP1-deficient malignancy that could be effectively treated with a zinc ionophore (clioquinol) approach. Chemotherapy 2015;4:pii:152.

44. Franklin RB, Zou J, Zheng Y, et al. Zinc ionophore (clioquinol) inhibition of human ZIP1-deficient prostate tumor growth in the mouse ectopic xenograft model: a zinc approach for the efficacious treatment of prostate cancer. Int J Cancer Clin Res 2016;3.

45. Faje A, Nachtigall L. Current treatment options for hyperprolactinemia. Expert Opin Pharmacol 2013;14:1611-25.

46. Cecenarro LA, Estario P, Estario ME, et al. Update on endocrinology: management of prolactinomas during pregnancy. Rev Fac Cien Med Univ Nac Cordoba 2015;72:170-4.

47. Auriemma RS, Grasso LF, Pivonello R, et al. The safety of treatments for prolactinomas. Expert Opin Drug Saf 2016;15:503-12.

48. Costa R, Santa-Maria CA, Scholtens DM, et al. A pilot study of cabergoline for the treatment of metastatic breast cancer. Breast Cancer Res Treat 2017;165:585-92. 